\section{IDRC public scandal: phase 2}

Phase 1 of the IDRC (International Development Research Centre) public scandal was the presence of a representative of the tobacco industry as chair of its Board (as Barbara McDougall was until March 2010). ${ }^{1}$ Phase 2 requires a question nobody asks: What did IDRC do with the Gates Foundation money under McDougall's stewardship? What did IDRC do with the $\$ 3505535$ that was not allocated to African grantees?

On December 2007, the Gates Foundation awarded \$5 274477 to IDRC to promote tobacco control in Africa. At the same time, McDougall, who was a Director of Imperial Tobacco Canada Ltd., became chair of the IDRC Board of Governors. Under her chairmanship, the African grantees apparently received $\$ 1768$ 942, which represents between $30 \%$ and $33 \%$ of the grant awarded by the Gates Foundation. What happened to the remaining 67\%?

\section{Véronique Le Clezio}

President, ViSa Mauritius, Floréal, Mauritius

\section{REFERENCE}

1. Hébert PC, Reddy KS, Jha P. Canada's perceived lack of leadership on global tobacco control. CMAJ 2010:182:E427

For the full letter, go to: www.cmaj.ca/cgi/eletters /182/10/E427\#551112

DOI: 10.1503/cmaj.110-2095

\section{Preoperative marking of limbs}

Knight and Wedge illustrate an important and familiar problem with marking limbs preoperatively with arrows or symmetric symbols. ${ }^{1}$ I have taken to marking limbs with either my initials or my signature. I insist that residents under supervision do this before I check the patient. Thus, even if the signature is barely legible, its owner, who is also the operating surgeon, can determine which is the original signature and which is the transferred mirror image.
I encourage each operating surgeon to consider this approach as a practical and safe marking method.

John A. Haggie MB ChB MD

Chief of Surgery, James Paton Memorial Hospital, Gander, NL

\section{REFERENCE}

1. Knight DMA, Wedge JH. Marking the operative site: a lesson learned. CMAJ 2010 Aug 3 [Epub ahead of print]

For the full letter, go to: www.cmaj.ca/cgi /eletters/cmaj.091860v1\#595170

DOI: 10.1503/cmaj.110-2106

\section{Multiple sclerosis: liberation procedure}

I saw Dr. Paul Hébert on Global National talking about Zamboni's work $^{1,2}$ as dilating veins in the brain. This is false: angioplasty is done on the jugular veins in the neck and the azygos vein in the chest. How do I know? Because I had this done in Poland a month ago. The next time someone talks about a medical procedure, perhaps he or she should have the facts straight first.

Jason Kaye

Sherwood Park. Alta.

\section{REFERENCES}

1. Stanbrook MB, Hébert PC. Access to treatment for multiple sclerosis must be based on science, not hope. CMAJ 2010;182:1151.

2. Zamboni P, Galeotti R, Menegatti E, et al. A prospective open-label study of endovascular treatment of chronic cerebrospinal venous insufficiency. J Vasc Surg 2009;50:1348-58.

For the full letter, go to: www.cmaj.ca/cgi/eletters /182/11/1151/\#595160

DOI: $10.1503 / \mathrm{cmaj} .110-2102$

I was heartened to hear that the liberation procedure was successful for Mr. Kaye. I fully acknowledge that I am not an expert in this area.

From the limited reports of this procedure in the literature, it appears that imaging of the jugular venous and azygous systems as well as the vertebrobasilar system may be undertaken, although this is not clear from Zamboni's report. ${ }^{1}$ To perform the imaging, one would, on occasion, advance a large catheter as far as the lower part of the brain. From the original description, balloon dilations and stent procedures are most commonly performed within the internal jugular system, as Kaye has suggested. As researchers initiate studies of cerebral venous drainage, venous imaging may eventually involve the brain's venous system. This may eventually be followed by attempted dilations of intracranial venous systems.

In news reports, I mentioned that catheters were inserted through various entry points, including the jugular vein, as discussed, or advanced as far as the brain for imaging beyond possible stenosis. At present, this appears technically correct based on the limited descriptions of the procedure.

My major point, however, was that the liberation procedure is still experimental and requires much more evaluation before it is made widely available. All procedures have risks, not only widely reported benefits. All vascular procedures include death as a known complication. As an aside, I should point out that we cause stenoses of the venous system in a large number of patients receiving dialysis because of long-term catheter use. As far as I am aware, we see no increase in the occurrence of multiple sclerosis in these patients.

Paul C. Hébert MD MHSc

Editor-in-Chief, CMAJ

\section{REFERENCE}

1. Zamboni P, Galeotti R, Menegatti E, et al. A prospective open-label study of endovascular treatment of chronic cerebrospinal venous insufficiency. J Vasc Surg 2009;50:1348-58.

For the full letter, go to: www.cmaj.ca/cgi/eletters /182/11/1151/\#595164

DOI: 10.1503/cmaj.110-2103

\section{Quality evidence important for quality guidelines}

AGREE $^{1,2}$ focuses on methodologic issues about guideline development and reporting. Although important, these issues are insufficient to ensure that 
recommendations are appropriate and valid, because methodologic rigour and validity are not necessarily correlated. ${ }^{3}$

In an assessment of pharyngitis guidelines by a panel familiar with AGREE, ${ }^{4}$ guidelines not citing European trials or the Cochrane review had higher AGREE scores than most other guidelines. Only 3 of 23 items in the AGREE instrument assesses the description of the evidence, although each item has the same weight. We therefore decided not to use AGREE in our comparison; we evaluated the evidence with an analysis of the references of the 10 existing guidelines. We concluded that high AGREE scores do not guarantee that the selection of the evidence has been adequately performed - even with the new item \#9 about strengths and limitations of the evidence - and that different items may have different relevance to the validity of the recommendations.

In a study on mass colorectal screening, guidelines were found to be equally valid regarding their (different) recom- mendations related to fecal occult blood tests, but no relation could be found between their methodologic AGREE quality and their content validity. ${ }^{5}$

Although AGREE is important in developing guidelines, the World Health Organization has also recognized the need to use more rigorous processes to ensure that health care recommendations are informed by the best available research evidence. ${ }^{6}$

\section{Jan Matthys}

Marc De Meyere

Department of General Practice and Primary Health Care, University of Ghent, Belgium

\section{REFERENCES}

1. Brouwers MC, Kho ME, Browman GP, et al. Development of the AGREE II, part 1: performance, usefulness and areas for improvement. CMAJ 2010; 182: 1045-52

2. Brouwers MC, Kho ME, Browman G, et al. Development of the AGREE II, part 2: assessment of validity of items and tools to support application. CMAJ 2010;182:E472-8.

3. Bruls A. AGREE II - Improving the quality of clinical care. Lancet 2010 July 2 [Epub ahead of print].

4. Matthys J, De Meyere M, van Driel ML, et al. Dif- ferences among international pharyngitis guidelines : not just academic. Ann Fam Med 2007;5:436-43.

5. Watine JC, Bunting PS. Mass colorectal cancer screening: methodological quality of practice guidelines is not related to their content validity. Clin Biochem 2008;41:459-66.

6. Schünemann HJ, Fretheim A, Oxman AD; WHO Advisory Committee on Health Research. Improving the use of research evidence in guideline development: 1. Guidelines for guidelines. Health Res Policy Syst 2006;4:13.

For the full letter, go to: www.cmaj.ca/cgi/eletters /182/11/1151/\#595071

DOI: $10.1503 / \mathrm{cmaj} .110-2105$

\section{Letters to the editor}

In submitting a letter, you automatically consent to have it appear online and/or in print. All letters accepted for print will be edited by $C M A J$ for space and style. Most references and multiple authors' names and full affiliations will appear online only. (The full version of any letter accepted for print will be posted at cmaj.ca.)

\section{The unique combination of ${ }^{\mathrm{P}}$ NORVASC ${ }^{\circledR}$ and ${ }^{\mathrm{P}}$ 'LIPITOR ${ }^{{ }^{1}}$}

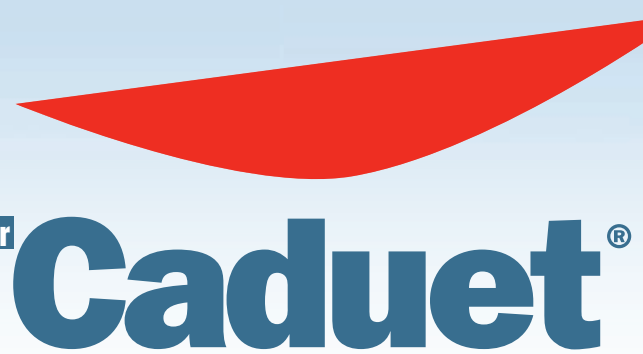

amlodipine besylate/atonvastatin calcium

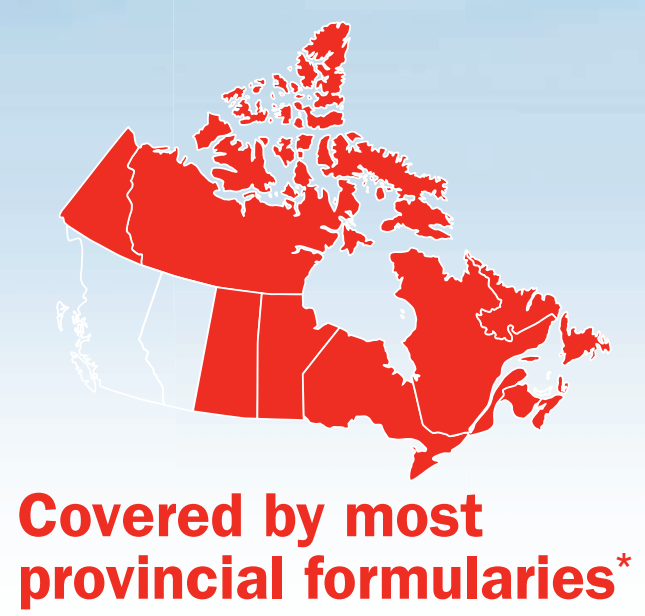

${ }^{*}$ See respective Formularies for details (not covered in $\left.B C, A B, P E I\right)$.

\section{Pfizer}

CADUET (amlodipine besylate/atorvastatin calcium) is indicated in patients for whom treatment with both amlodipine besylate and atorvastatin calcium is appropriate, specifically, patients at cardiovascular risk. Please refer to the Product Monographs of NORVASC (amlodipine besylate) and LIPITOR (atorvastatin calcium). Please consult the CADUET Product Monograph to obtain information on the indications, contra-indications, warnings, precautions, safety and dosing. 